\title{
Apropriação tecnológica na economia do conhecimento: inovação e propriedade intelectual de software na América Latina ${ }^{1}$ \\ Paulo Bastos Tigre ${ }^{2}$ \\ Felipe Silveira Marques ${ }^{3}$
}

\section{Resumo}

Os direitos de propriedade intelectual constituem um instrumento de estímulo à inovação, embora possam também obstaculizar a difusão do conhecimento na economia. Este artigo discute tal conflito na área de software, onde a proteção por patentes é dificultada pelo fato dos ativos serem intangíveis e replicáveis praticamente sem custos. Tomando por base o caso latino-americano, as práticas de proteção à propriedade intelectual são discutidas à luz de sua eficácia enquanto instrumento de estímulo à inovação e difusão das tecnologias da informação. A metodologia utilizada inclui análise do desenvolvimento da indústria de software no subcontinente, das formas de proteção adotadas pelas empresas, das legislações existentes e exame das patentes de software submetidas ao Instituto Nacional da Propriedade Industrial. O artigo conclui que é necessário harmonizar interesses conflitantes que transcendem o aspecto técnico, levando em consideração a necessidade de assegurar novos modelos de negócios e respeitar os acordos internacionais vigentes.

Palavras-chave: Propriedade intelectual; Software - América Latina; Inovação tecnológica; Difusão tecnológica.

\begin{abstract}
Technology appropriation in knowledge economy: innovation and intellectual property in Latin American software industry

Intellectual property rights aim at providing incentives for innovation, but can also constitute a burden for technological diffusion. This article discusses the conflicts arising from software patent protection, an area in which the assets are intangible and replicable at almost no cost. Current practices of intellectual property (IP) protection in Latin America are discussed based on their efficiency in stimulating information technologies innovation and diffusion. The methodology adopted includes the analysis of regional software industry development, firms' strategies to protect IP, legislation and the examination of software patents submission at the Brazilian IP Office (INPI). It concludes that harmonizing conflicting interests among existing and new business models and international agreements is a major task that goes beyond pure technical considerations.
\end{abstract}

Key words: Intellectual property, Software - Latin America, Innovation, Technology diffusion. JEL L170, L870, O320, O340, M150.

(1) Trabalho recebido em agosto de 2007 e aprovado em julho de 2008.

(2) Professor titular da Universidade Federal do Rio de Janeiro (UFRJ), Rio de Janeiro, RJ, Brasil. E-mail: pbtigre@ terra.com.br.

(3) Economista do Departamento de Prioridades do Banco Nacional de Desenvolvimento Econômico e Social (BNDES) e doutorando em Economia da Indústria e da Tecnologia pelo Instituto de Economia da Universidade Federal do Rio de Janeiro (UFRJ), Rio de Janeiro, RJ, Brasil. E-mail: . 
Paulo Bastos Tigre / Felipe Silveira Marques

\section{Introdução}

A relação entre inovação e direitos de propriedade intelectual sempre levantou controvérsias, dada a grande heterogeneidade existente nas formas de apropriação dos resultados de esforços de inovação tecnológica. Os direitos de propriedade intelectual constituem essencialmente um estímulo à inovação, recompensando o inovador dos riscos inerentes à atividade. Por outro lado, pode representar um obstáculo à ampla difusão do conhecimento na economia, na medida em que dão o direito ao detentor de patentes de excluir terceiros do acesso a inovações. Harmonizar o incentivo ao inovador com o amplo acesso à torrente de informações que brota da dinâmica tecnológica constitui um desafio que transcende $o$ aspecto puramente técnico.

$\mathrm{Na}$ área de software, a controvérsia sobre as formas de proteção da propriedade intelectual está associada à natureza única dos programas que desempenham funções técnicas por meio de algoritmos. Ao invés de enfatizar o meio físico, o software é intangível e pode ser replicado praticamente sem custos. O software é caro de se produzir e barato de se reproduzir, ou seja, possui altos custos fixos e baixos custos marginais (Shapiro; Varian, 1999). Por isso, seu preço é fixado de acordo com o valor que o consumidor está disposto a pagar por ele, e não como função direta dos custos de produção.

O título de propriedade intelectual atribuído internacionalmente ao software é o direito de autor ou copyright. Alguns países, entretanto, concedem patentes de invenções relativas a serviços financeiros, vendas eletrônicas, métodos de negócios e publicidade pela Internet que se expressam por meio de programas de computador. A demanda pelo patenteamento de software deve-se ao fato de que o copyright protege apenas as "expressões literais" dos programas de computador. Como o valor do software não está apenas na sua forma, mas também nas "ideias" nele contidas, a patente passa a ser uma forma de apropriação tecnológica mais forte. Ela protege a funcionalidade do programa e não apenas a forma como foi escrito. Em termos práticos, o copyright protege contra a pirataria enquanto as patentes evitam a cópia por concorrentes.

Um dos principais argumentos a favor das patentes de inovações implementadas por meio de software é que o conceito do programa precisa ser protegido para favorecer a atividade inventiva. Na medida em que o software interage com o hardware, oferecendo um conjunto de instruções que permitem que a máquina desempenhe uma determinada função, argumenta-se que ambos precisam ser protegidos. Por outro lado, existe oposição ao patenteamento de software e modelos de negócios em função de suas implicações econômicas e sociais. Argumenta-se que a proteção por patentes pode inibir a competição em função das características da inovação em software. Ao contrário do que ocorre 
em áreas onde a inovação é centralizada, o desenvolvimento de software envolve, tipicamente, a cumulatividade, a inovação sequencial e o reuso de módulos em novos programas.

Este artigo analisa as práticas de propriedade intelectual adotadas na indústria latino-americana de software. A principal questão discutida é a eficácia das patentes de software como instrumento de estímulo à inovação e difusão das tecnologias da informação e da comunicação (TIC). Como garantir os legítimos direitos de apropriação tecnológica sem reduzir o espaço para a diversidade e convivência de modelos de negócios distintos? A metodologia utilizada inclui análise do banco de dados de patentes (SIMPI) do Instituto Nacional da Propriedade Industrial. Diante dos impasses atuais no debate sobre o regime de propriedade intelectual do software no âmbito do Acordo TRIPS (trade-related aspects of intellectual property rights) da Organização Mundial do Comércio, o aprofundamento do tema é importante para balizar as negociações bilaterais e multilaterais em curso envolvendo países latino-americanos.

\section{A indústria de software e serviços na América Latina}

Para entender a importância dos direitos de propriedade intelectual na indústria latino-americana de software precisamos inicialmente avaliar suas características, dinâmica e relevância na indústria global. A Tabela 1 apresenta os dados de vendas, exportações e emprego em oito países da América Latina. ${ }^{4}$ Empresas de software e serviços de informática (SSI) instaladas nos principais mercados da região obtiveram um faturamento conjunto de US\$ 17 bilhões, equivalentes a pouco menos de $3 \%$ do mercado mundial. Entre eles, o Brasil constitui o principal mercado com cerca de $60 \%$ do total. Cabe lembrar que o valor registrado das atividades de SSI é geralmente subestimado, já que parte das atividades não é contabilizada pelo fato de serem realizadas internamente pelas empresas usuárias. Além disso, alguns serviços são efetuados de maneira informal, não aparecendo, portanto, nas estimativas de faturamento.

As empresas de SSI empregavam formalmente 371,2 mil pessoas nos oito países estudados em 2005. No entanto, o número real de trabalhadores no setor pode ser substancialmente maior devido não só ao desenvolvimento de software e serviços pelos próprios usuários mas também por causa da prática, amplamente adotada no setor, de utilizar contratos informais de trabalho. Mochi e Hualde (2007) estimam, para o caso do México, que o número efetivo de trabalhadores em SSI é cinco vezes maior do que o registrado nas empresas especializadas. Tomando este número como base, chegaríamos a 1,8 milhões de trabalhadores, o

(4) Os dados foram obtidos por consultores de um projeto da Cepal e apresentam algumas diferenças em relação aos de Witsa (2006), principalmente para a Colômbia, cuja estimativa não inclui empresas locais de serviços. Um dos motivos é que os dados são de produção e não de gasto. 
que equivale a $1,6 \%$ da força de trabalho total da região. Nos países da OECD, que apresentam maior difusão de TI, em contraste, a força de trabalho no setor corresponde a $4 \%$ do total, dado que confirma a coerência de tais estimativas.

Ainda no tocante ao fator trabalho, verificamos que o perfil de empregos das nove principais empresas multinacionais que atuam na região varia significativamente em função do segmento de mercado visado. As subsidiárias de empresas dedicadas exclusivamente à prestação de serviços empregam em média 16,4 pessoas para cada milhão de dólares de vendas. Já as empresas que oferecem software produto, por trazerem soluções prontas do exterior, geram somente 2,6 empregos por milhão (Tigre; Marques, 2007). Como não se desenvolvem localmente, as subsidiárias de empresas de software produto tampouco exportam.

As exportações de software e serviços da região são estimados em cerca de US\$ 1 bilhão. Em termos relativos, a Costa Rica, o Uruguai e a Argentina são os países que mais exportam em relação ao faturamento total com 44,5\%, 39,5\% e $18,3 \%$, respectivamente. Estes três países são justamente aqueles que apresentam os melhores indicadores educacionais no subcontinente, sugerindo que a qualificação da força de trabalho constitui um fator chave nas exportações de software e serviços. Chile e México, com 5\%, estão próximos à média da amostra de 6\%. O Equador, com 12\%, está em situação intermediária. Já o Brasil e a Colômbia exportam apenas $3 \%$ do faturamento total.

Tabela 1

Faturamento, emprego e exportações de SSI em países selecionados, 2005

\begin{tabular}{l|r|r|r|r|r|c}
\hline & $\begin{array}{c}\text { Fatura- } \\
\text { mento } \\
\text { (US\$ milhões) }\end{array}$ & $\begin{array}{c}\text { Emprego } \\
\text { Setor } \\
\text { (em mil } \\
\text { pessoas) }\end{array}$ & $\begin{array}{c}\text { Exportações } \\
\text { (US\$ milhões) }\end{array}$ & $\begin{array}{c}\text { Fatura- } \\
\text { mento / } \\
\text { PIB }\end{array}$ & $\begin{array}{c}\% \text { do } \\
\text { emprego } \\
\text { total }\end{array}$ & $\begin{array}{c}\text { Exportação } \\
\text { / Fatura- } \\
\text { mento }\end{array}$ \\
\hline Argentina & 1.342 & 32,0 & 245,1 & 0,74 & 0,20 & 18,3 \\
\hline Brasil & 10.347 & 219,3 & $314,0^{(\mathrm{a})}$ & 1,30 & 0,25 & 3,0 \\
\hline Chile & $1.385^{(\mathrm{a})}$ & $24,9^{(\mathrm{a})}$ & $68,8^{(\mathrm{a})}$ & 1,20 & 0,42 & 5,0 \\
\hline Colômbia & $340^{(\mathrm{a})}$ & $31,7^{(\mathrm{a})}$ & $10,3^{(\mathrm{a})}$ & 0,28 & 0,16 & 3,0 \\
\hline Costa Rica & 248 & $\mathrm{nd}$ & 110,3 & 1,28 & nd & 44,5 \\
\hline Equador & $90^{(\mathrm{a})}$ & $4,5^{(\mathrm{a})}$ & $10,7^{(\mathrm{a})}$ & 0,25 & 0,07 & 11,9 \\
\hline México & 3.128 & 53,9 & 164,0 & 0,41 & 0,13 & 5,2 \\
\hline Uruguai & 265 & $4,9^{(\mathrm{a})}$ & 104,5 & 1,57 & 0,30 & 39,5 \\
\hline Total & 17.145 & 371,2 & $1.027,7$ & 0,83 & 0,21 & 6,0 \\
\hline
\end{tabular}

(a) Dados de 2004.

Fonte: CAMTIC (2006, p. 3) para Costa Rica; Tigre e Marques (2007) para demais países. 
Apropriação tecnológica na economia do conhecimento: inovação e propriedade intelectual de software...

O Uruguai é o país onde o setor tem maior peso relativo no PIB $(1,57 \%)$, seguido do Brasil (1,30\%), Costa Rica $(1,28 \%)$ e Chile $(1,20 \%)$. O software tem uma participação relativamente menor no México $(0,41 \%)$, Colômbia $(0,28 \%)$ e Equador $(0,25 \%)$. A Argentina $(0,74 \%)$ se encontra em situação intermediária, próxima à média dos oito países, de $0,83 \%$.

\section{Inovação e propriedade intelectual na indústria de software}

O conceito de software como um componente distinguível de um sistema computacional, segundo Mowery e Rosenberg (2005), nasceu nos anos 1950 com o advento da arquitetura de Von Neumann dos computadores com programas armazenados. Porém, o software permaneceu intimamente ligado ao hardware, e o desenvolvimento de uma indústria de software nos Estados Unidos só começou realmente quando os computadores passaram a ser produzidos em grandes quantidades. No final dos anos 60, os produtores de computadores começaram a "desembutir" suas ofertas, separando o preço e a distribuição do software, fato que estimulou a entrada de produtores independentes de programas aplicáveis a computadores de grande porte.

A invenção do microprocessador pela Intel em 1971 revolucionou a tecnologia de hardware ao integrar toda a Unidade Central de Processamento (CPU, na sigla em inglês) de um computador em um único chip. Com a maior integração de circuitos, a disponibilidade de memória deixou de ser um recurso escasso para se transformar em uma solução virtualmente ilimitada. Como consequência, multiplicou-se a oferta, a custos declinantes, da capacidade de armazenamento, processamento e transmissão de informação digitalizada, permitindo sustentar uma crescente expansão das aplicações de bens da informação.

O crescimento do valor atribuído ao software na cadeia de valor resultou em maior interesse por parte da indústria em proteger seus ativos intangíveis. $\mathrm{O}$ software passou a ser um produto à parte, cobrado separadamente do hardware, o que propiciou o desenvolvimento de uma indústria independente. Tal indústria passou a reivindicar maior proteção legal, visando reaver os investimentos realizados no desenvolvimento de programas e impedir a circulação de cópias não autorizadas. Diante dessa nova situação, chegou-se a um consenso no âmbito da Organização Mundial de Propriedade Intelectual (OMPI) de que os programas de computador precisavam ser protegidos, dando origem a intensas discussões sobre o papel do regime de Propriedade Intelectual (WIPO, 2004, p. 436).

$\mathrm{O}$ advento da Internet facilitou ainda mais a distribuição e circulação do software, acentuando suas características de intangibilidade e fácil distribuição. $\mathrm{O}$ valor de uma tecnologia geralmente depende das condições de apropriabilidade, 
ou seja, da possibilidade de se manter o controle monopolista sobre essa tecnologia por um determinado período de tempo. Tal controle é geralmente exercido por meio da propriedade intelectual sobre bens imateriais, principalmente por meio de patentes ou direitos autorais. Em alguns casos, a tecnologia não é patenteável e a proteção é mantida por segredo industrial. Uma tecnologia não protegida e facilmente imitável leva os rendimentos monopolistas de uma inovação à quase zero (Dosi et al., 2003).

Por outro lado, uma apropriação exclusiva e prolongada de direitos sobre inovações pode restringir a difusão do conhecimento. Isso ocorre não apenas porque o monopólio resulta em maiores custos para os usuários, mas principalmente pela pouca transparência técnica oferecida. O software proprietário constitui uma "caixa preta" cujo código fonte não está aberto a terceiros. Em consequência, há pouca troca de conhecimentos e insuficientes incentivos para o processo de aprendizado interativo. As tecnologias proprietárias quando bem sucedidas constituem um monopólio natural em função das economias de rede que geram para seus usuários. Por meio do processo conhecido como feedback positivo (Shapiro; Varian, 1999) onde o mais forte fica cada vez mais forte, o proprietário da tecnologia pode acabar monopolizando o mercado de bens e produtos.

Diante das grandes diferenças existentes entre empresas de software com relação a tamanho, modelos de negócios, mercados e tecnologias utilizadas estabeleceu-se um conflito internacional quanto à forma de proteção a ser conferida ao software produto. Dois grupos podem ser identificados como polarizadores da discussão.

O primeiro grupo é constituído pelas grandes empresas do setor de TIC que exercem uma considerável pressão junto a organismos multilaterais e governos nacionais não só pela manutenção do status quo como também pelo aumento da abrangência da patenteabilidade de invenções implementadas em computador. Na Europa, um grupo formado por Nokia, Philips, Siemens, Ericsson e Alcatel enviou um documento à União Européia, estimando um prejuízo de 15 a 18,5 bilhões de euros de seus gastos com pesquisa de desenvolvimento (P\&D), caso não fossem permitidas patentes relacionadas a software (Silva, 2007).

Outro argumento é que restrições às patentes de software irão ter implicações negativas na economia da Europa como um todo e acabarão por acarretar a perda de milhares de empregos de alta qualificação em pesquisa e desenvolvimento (P\&D). As grandes empresas alegam que uma diretiva estabelecendo limites a patentes de software poderia induzir à fuga de especialistas e investimentos para os Estados Unidos e, portanto, o fortalecimento do regime de propriedade intelectual seria uma forma de defender a Europa da competição com os Estados Unidos. 
O segundo grupo, contrário ao fortalecimento do sistema de proteção à propriedade intelectual em software, é formado por um conjunto abrangente de atores, incluindo a comunidade de software livre e código aberto, instituições acadêmicas e associações de pequenas e médias empresas. Eles argumentam que as patentes relacionadas a software irão desestimular a inovação e farão com que os desenvolvedores de softwares corram o risco de serem processados por grandes empresas (Andrade et al., 2007).

A exemplo de outros bens imateriais, o software se caracteriza como um bem não competitivo, ou seja, pode ser compartilhado por todos sem custos adicionais. $\mathrm{O}$ fato de uma pessoa utilizar um programa não priva ninguém mais da possibilidade de fazer o mesmo, em igualdade de condições (Lemos, 2005). Por este motivo, desde 1980, vêm surgindo modelos alternativos de produção e distribuição. Questionando a necessidade de licenças que, cada vez mais, restringiam a liberdade dos usuários, as comunidades de software livre adotam diferentes iniciativas, como a criação de sistemas operacionais e aplicativos com código-fonte aberto e que são distribuídos gratuitamente mediante uma licença de uso específica.

Os adeptos do software aberto defendem e acreditam que um regime sem patentes que estimule o acesso ao conhecimento e a competição entre empresas independentes é uma forma preferível de estimular a inovação no setor e garantir a interoperabilidade entre os programas, sistemas e redes. Eles argumentam que as patentes de software prejudicam o processo de padronização e aprisionam usuários em tecnologias proprietárias. O patenteamento de modelos de negócios é visto como um fator de distorção da competição no mercado, pois confere direitos exclusivos desproporcionais em relação aos investimentos realizados pelo detentor da patente. Tendo em vista o custo desproporcional imputado à sociedade pela concessão de direitos exclusivos, métodos de negócios deveriam ser considerados de domínio público, a exemplo das leis da natureza e dos princípios científicos.

\section{Formas de proteção à propriedade intelectual em software}

Os mecanismos legais disponíveis para a proteção de propriedade intelectual são a patente, o direito autoral e, num contexto mais restrito, existe também a proteção de marcas e símbolos de negócio, mediante o seu registro. Além disso, são utilizadas formas técnicas de proteção de forma a assegurar o segredo de negócio. Frequentemente, um único produto utiliza mais de uma dessas formas de proteção.

A indústria de software é naturalmente segmentada entre produtos e serviços, embora possa haver uma combinação entre as duas modalidades. O software produto ou pacote de software é uma aplicação preparada previamente 
que serve a um conjunto amplo de clientes. A competitividade neste segmento é definida pela capacidade de desenvolvimento técnico e de comercialização de produtos em massa. Os investimentos necessários para desenvolver e lançar produtos são altos e o retorno depende de sua aceitação pelo mercado. O software produto se diferencia dos serviços de software em função de suas características concorrenciais, pois envolve ganhos crescentes de escala. Segundo Roselino (2006), o desenvolvimento de software pacote envolve, de modo geral, uma menor interação entre a empresa de software e o potencial demandante, aumentando a necessidade de proteção legal.

\subsection{Copyrights}

Tradicionalmente, o software é protegido por copyrights. O acordo TRIPS da Organização Mundial do Comércio (OMC) referendou, em 1994, esta interpretação, dispondo no artigo 10 que "programas de computador, em código fonte ou objeto, serão protegidos como obras literárias segundo a Convenção de Berna". O copyright é o regime de proteção conferido especificamente às criações literárias, artísticas e científicas. Para a obtenção de um registro de direito autoral é necessário apenas o requisito de originalidade. Este registro confere ao autor o direito exclusivo de utilizar, fruir e dispor da obra literária, artística ou científica, ou seja, basicamente, o de impedir que terceiros copiem o que foi criado, sem o seu consentimento. O registro do software é opcional, já que o direito do autor nasce com a obra e, consequentemente não se aplica a uma concepção abstrata ou simples ideia, mas sim a algo escrito, pintado ou esculpido, expressando uma ideia em uma forma concreta de criação.

O copyright protege uma criação original de software garantindo ao criador um controle exclusivo, incluindo o direito de vender e licenciar o trabalho e excluindo outros, como os de se apropriar, replicar e vender o programa sem permissão. O sistema de proteção não exclui a possibilidade de outros agentes desenvolverem trabalhos semelhantes de forma independente, baseados nas mesmas ideias ou propósitos. O desenvolvedor original pode também manter controle sobre trabalhos derivados, tais como novas versões. O software é geralmente licenciado a qualquer usuário, mas a licença pode conter termos e condições arbitrárias de uso, pagamento e disseminação, incluindo prazos, abrangência da licença e formas de pagamento.

O registro de direito autoral protege tanto o código-fonte quanto o códigoobjeto (ou código-executável) relativo ao software. Tal proteção está relacionada à "forma de expressão da ideia" e não à "aplicação da ideia" que o software executa. As criações envolvendo programas de computador eram consideradas uma extensão do pensamento, atos puramente mentais, que não se enquadram como invenções. 
No entanto, à medida que o software efetivamente comanda todo o sistema computacional, levando-o a realizar múltiplas funções, fica claro que ele representa muito mais do que é literalmente expresso pelo seu código. Sob esse argumento, as empresas de software incluíam, na solicitação de registro de direito autoral, aspectos relacionados às funções executadas pelo programa. A tutela de direito autoral, por estar relacionada às criações artísticas, científicas e literárias, é uma proteção de forma, de aspectos literais, não cabendo qualquer proteção a funcionalidades. Assim, tais artifícios foram negados judicialmente, posto que os aspectos funcionais não se enquadravam na categoria de direito autoral.

Segundo o Manual Frascati (OCDE, 2002, p. 46), para um projeto de desenvolvimento de software ser classificado como Pesquisa e Desenvolvimento, sua consecução deve depender de avanços técnicos ou científicos ou o objetivo deve ser a resolução sistemática de uma incerteza científica ou tecnológica. O uso de um software para uma nova aplicação ou propósito não constitui necessariamente um avanço. Desta forma, é difícil identificar o que é de fato uma inovação no setor. Valimaki (2005, p. 69) aponta que muitos renomados programadores não se reconhecem como inovadores, mas, sim, como autores. Estes comparam o desenvolvimento de um novo software à escrita e afirmam que um novo software não é "descoberto", mas implementado. Nesse contexto, o copyright constitui a forma mais adequada de propriedade intelectual para o software.

Na tradição do direito autoral, a lei protege a forma de expressão de um programa, e não a sua ideia ou utilidade. A interpretação corrente é de que as telas e relatórios de um programa podem ser copiados sem violação dos direitos autorais; o que não pode ser copiado é seu código-fonte (Veiga, 1998). Também não constitui ofensa aos direitos do titular a ocorrência de semelhanças de um programa a outro, quando se der por força das características funcionais da aplicação, da observância de preceitos normativos e técnicos ou de limitação de forma alternativa para a sua expressão. Existem ainda casos de realização de uma única cópia de salvaguarda e da citação parcial para fins didáticos que são explicitamente permitidos na lei. A lei exclui explicitamente os direitos morais do autor, exceto o direito de reivindicar a paternidade do programa e de se opor a quaisquer modificações que possam prejudicar sua honra ou reputação. Além disso, são reconhecidos como pertencentes exclusivamente ao empregador os direitos de propriedade de programas desenvolvidos sob o vínculo empregatício. Para usufruto dos direitos de autor decorrentes do desenvolvimento de programas de computador não há necessidade de qualquer formalidade ou registro. 
Paulo Bastos Tigre / Felipe Silveira Marques

\subsection{Patentes de software}

As patentes relacionadas aos sistemas de controle dedicado, definidas como "software embarcado" sempre foram admitidas pelas instituições de registro de patentes. Programas de controle de equipamentos e sistemas como freio ABS em automóveis, programas embutidos em telefones celulares e máquinas de lavar, não têm sido objeto de controvérsias relevantes. Porém, observa-se claramente que a maioria dos debates relativos à patenteabilidade das invenções implementadas por computador gira em torno do critério, escopo e forma de proteção em que devem ser concedidas patentes relacionadas ao "software puro", ou seja, softwares cuja aplicação destina-se a computadores de aplicações gerais, tais como o microcomputador pessoal (Andrade et al., 2007).

A patente confere ao seu detentor o direito de impedir terceiros de produzir, usar, vender ou importar o objeto patenteado (processo ou produto) sem o seu consentimento. Deve-se levar em consideração não "a ideia tal como foi expressa", mas sim a sua aplicação prática. Uma patente de invenção somente é concedida quando o objeto criado possui os seguintes requisitos:

- Novidade: o objeto não está compreendido no estado da técnica, ou seja, não pode ter sido anteriormente disponibilizado ao público por qualquer tipo de mídia.

- Atividade inventiva: o objeto não deve ser percebido como óbvio, no âmbito do estado da técnica, por um técnico no assunto.

- Aplicação industrial: o objeto deve ser suscetível de aplicação industrial, ou seja, de poder ser utilizado e/ou produzido pela indústria.

- Suficiência descritiva: deve descrever o objeto de forma clara e suficiente de modo que um técnico no assunto possa reproduzi-lo.

Uma importante diferença em relação ao copyright é que o proprietário da patente pode excluir os demais de seu uso, mesmo se os novos programas tiverem sido desenvolvidos de forma independente. Esse aspecto é o que mais preocupa as pequenas e médias empresas. A concessão de uma patente poderá excluir empresas que chegaram a programas similares sem conhecimento prévio do produto original.

As patentes começaram recentemente a serem concedidas a software e processos de negócios que usualmente incorporam software aplicativo. Apesar da exclusão de programas para computador em si da proteção por patente estar contemplada no art. 52 da European Patent Convention (EPC), bem como nas legislações nacionais, milhares de patentes têm sido concedidas pelo European Patent Office (EPO) e por alguns escritórios de estados membros da União 
Apropriação tecnológica na economia do conhecimento: inovação e propriedade intelectual de software...

Européia (UE). Nos Estados Unidos, a concessão de patentes tem sido ainda mais liberal, tanto no processo de análise quanto no escopo das inovações.

Com o intuito de forçar uma proteção mais ampla, empresas de TIC passaram a submeter, sistematicamente, depósitos de pedidos de patente envolvendo programas de computador. Tal ação rendeu frutos, posto que hoje em dia algumas instituições envolvidas em PI já admitem que os programas de computador atribuam um caráter técnico ao objeto, deixando de ser considerado apenas um ato mental abstrato.

As grandes empresas de software produto, que vendem pacotes padronizados, são as que mais pressionam os escritórios de Propriedade Intelectual para uma proteção mais abrangente. Elas procuram criar novas condições técnicas e jurídicas para proteger seus produtos. Entretanto, os critérios de patenteabilidade para as invenções implementadas em computador não são claros e, em decorrência disso, vêm sendo interpretados de forma diferente nos diversos países, gerando problemas comerciais transfronteiras.

O advento da Internet facilitou ainda mais a distribuição e circulação do software, acentuando as características descritas por Lemos (2005) como res commune, isto é, bens de todos e, ao mesmo tempo, bens de ninguém. Uma vez que a circulação de cópias não autorizadas é tecnicamente difícil, a indústria de TIC tem se preocupado em criar novas formas jurídicas de proteger seus ativos intangíveis por meio das patentes.

A concessão de patentes de software pode resultar na concentração do mercado. O poder de inovação das pequenas empresas é inibido pela patente, já que o seu alto custo de obtenção - que varia de 10.000 euros nos EUA a quase 50.000 euros no EPO - aumenta o risco de serem excluídas do mercado, por não terem condições de arcar com tais custos. Outra consequência das patentes de software seria o aumento nos pedidos de patente e, portanto, no tempo que elas levam para serem concedidas, aumentando, assim, a incerteza legal do sistema. As pequenas empresas não seriam capazes de competir em bases iguais com grandes corporações que possuem advogados especializados com possibilidade de requisitar centenas ou milhares de patentes anualmente e iniciar processos legais indiscriminadamente como medida de intimidação.

Outro argumento contra o patenteamento é que produtos de software tendem a ser sistemas construídos a partir de vários subsistemas preexistentes. Permitir a patente desses componentes poderia implicar no pagamento simultâneo de várias licenças, de forma a poder comercializar um dado produto, resultando em um custo maior para a sociedade. Dessa forma, as grandes empresas seriam favorecidas devido aos seus grandes portfólios de patentes e, consequentemente, grande poder de barganha para negociar licenças cruzadas entre si. 
Paulo Bastos Tigre / Felipe Silveira Marques

Os opositores das patentes de software argumentam ainda que os bancos de dados utilizados na busca nos escritórios de patentes não contemplam grande parte do estado da técnica para softwares, dificultando significativamente o procedimento de exame de patente na aferição de novidade e não obviedade. Em consequência, corre-se o risco de que softwares que já fazem parte do estado da técnica sejam apropriados indevidamente por meio de patentes. Dessa forma, as patentes de software teriam, na prática, uma presunção de validade menor do que patentes em outras áreas.

\subsection{Formas técnicas de proteção}

Muitas empresas, principalmente de pequeno e médio porte, não utilizam meios jurídicos para proteger sua propriedade intelectual, preferindo recorrer a elementos tecnológicos. Os meios técnicos de proteção ao software incluem os seguintes procedimentos:

- Autenticação digital

- Criptografia

- Controle de acesso

- Auditoria de sistemas

- Segregação de funções

A eficácia desses procedimentos pode variar segundo a complexidade do software e o mercado para o qual ele se dirige. Empresas que desenvolvem produtos sob encomenda de usuários específicos não necessitam de registros de software, pois podem controlar o acesso de usuários e criptografar as comunicações que envolvem o programa. Já os provedores de produtos voltados para o grande público utilizam códigos e protocolos para dificultar a cópia ilegal e monitorar as ações dos usuários. Independentemente da questão legal, as formas técnicas de proteção estão ganhando crescente importância nas estratégias competitivas adotadas na indústria de software.

\section{Propriedade intelectual de software na América Latina}

Em conformidade com a Convenção de Berna, os países latino-americanos conferem ao software a proteção autoral concedida às obras literárias. Vários países revisaram recentemente seu marco regulatório referente à propriedade intelectual de forma a se adequar à legislação sugerida pelo acordo TRIPS. Hoje existem apenas diferenças pontuais nas políticas adotadas pelos países da região em relação à PI. Por exemplo, a Argentina, ao contrário do Brasil, do Chile e da Colômbia, não inclui obras multimídias em sua lei de proteção ao software. Outra diferença é observada nos órgãos responsáveis pelo registro de software. Enquanto no Brasil, Chile, Equador e México o registro é feito pela instituição que concede 
também a patente, na Colômbia e no Uruguai ele é realizado pela instituição que faz registro de livros e outras obras, e na Argentina é feito por uma associação do setor.

Tabela 2

Legislação sobre proteção de software na América Latina

\begin{tabular}{|c|c|c|c|c|}
\hline País & Lei & Ano & Forma de proteção & Quem faz o registro \\
\hline Argentina & 11.723 & 1998 & Direito de autor & Cámara de Empresas de Software (CESSI) \\
\hline Brasil & 9.609 & 1998 & Direito de autor & $\begin{array}{l}\text { Instituto Nacional de Propriedade } \\
\text { Intelectual (INPI) }\end{array}$ \\
\hline Chile & 17.336 & 1970 & Direito de autor & $\begin{array}{l}\text { Departamento de Derechos de la } \\
\text { Propiedad Intelectual }\end{array}$ \\
\hline Colômbia & 603 & 2000 & Direito de autor & Dirección Nacional de Derechos de Autor \\
\hline Equador & 83 & 1998 & Direito de autor & $\begin{array}{l}\text { Instituto Ecuatoriano de la Propiedad } \\
\text { Intelectual (IEPI) }\end{array}$ \\
\hline México & 122 & 1996 & Direito de autor & $\begin{array}{l}\text { Instituto Mexicano de la Propiedad } \\
\text { Intelectual }\end{array}$ \\
\hline Uruguai & 17.616 & 2003 & Direito de autor & Consejo de Derechos de Autor \\
\hline
\end{tabular}

Fonte: Elaboração própria a partir de López e Ramos (2007, p. 81-88) para a Argentina; Marques (2007, p. 65-66) para o Brasil; Alvarez (2007, p. 37) para o Chile; Rodríguez (2007, p. 38-39) para a Colômbia; Mireles (2007, p. 64) para o Equador; Mochi e Hualde (2007, p. 61-63) para o México; e González (2007, p. 46) para o Uruguai.

Embora a legislação preveja a proteção por direito de autor, alguns países da região concedem patentes de software, registradas como patentes de invenção. No Chile, em 1991, havia apenas um pedido de patente; em 1998, oito; em 2004, 123 e, em 2005, 140 (Alvarez, 2006, p. 37). Devido ao alto custo - entre US\$1,3 mil e US\$ 3,7 mil - as empresas de capital chileno não costumam solicitar patentes de software.

\subsection{O caso das patentes de software no Brasil}

O caso do Brasil merece ser destacado pelo fato de ter um histórico de efetiva concessão de patentes de software e também por ser o principal mercado na região. Até 1998, o país adotava uma política própria de propriedade intelectual para software (Andrade et al., 2007). Tal política começou a sofrer pressões em função da inclusão do tema de propriedade intelectual na pauta de negociações da Rodada Uruguai do então General Agreement for Trade and Tariffs (GATT) que antecedeu a OMC. Em consequência, o Brasil reformulou sua legislação sobre direitos autorais, estabelecendo o direito autoral para programas de computador pelo prazo de cinquenta anos.

Apesar de não incluir explicitamente patentes de software, esse tipo de proteção vem sendo efetivamente concedido, seguindo a pratica adotada na 
Europa e nos Estados Unidos. O software é geralmente patenteado como uma invenção implementada por computador. Para isso, os solicitantes argumentam que, conforme o acordo TRIPS (artigo 27.1), patentes devem ser disponíveis para invenções em todos campos tecnológicos, devendo, portanto, a proteção patentária se estender também ao software.

Em uma busca no sistema de patentes do Instituto Nacional da Propriedade Intelectual (SINPI) realizada em março de 2007 foram identificadas 590 patentes de software decididas (deferidas e indeferidas). A busca utilizou as seguintes palavras chaves: "Computador, microprocessador, microcontrolador, notebook, programa ou software". Foram considerados apenas pedidos de patente de invenção (PI), que é a natureza adequada para os pedidos relacionados a programas de computador. Dos 590 pedidos decididos, 439 foram deferidos (74\%) e 151 indeferidos (26\%). As patentes de invenção concedidas são dos seguintes tipos:

- Sistema Operacional (SO)

- Interfaces de usuário (IU)

- Telecomunicações (TC)

- Processamento gráfico (PG)

- Controle de impressão (PR)

- Automação industrial (AU): controle de freios de trens e elevadores, controle automático de marchas de automóveis

- Codificação de dados (ML)

- Distribuição e seleção de programas de televisão

- Processamento de linguagem com sistemas de reconhecimento de voz (PL)

- Controle de instalações elétricas (EE)

- Edição de texto (ET).

A Tabela 3 mostra que, do total de 590 pedidos de patentes decididos, 512 foram solicitados por não residentes $(87 \%)$ contra apenas 78 de residentes no país (13\%). Das patentes solicitadas por não residentes, a maioria (83\%) foi efetivamente concedida. Em contraste, apenas $18 \%$ dos pedidos feitos por residentes foram deferidos. Tais pedidos foram feitos principalmente por pessoas físicas e a maior parte dos indeferimentos foi atribuída à insuficiência descritiva. Já as patentes concedidas a não residentes foram solicitadas por empresas que, em sua grande maioria, já haviam obtido tal registro no exterior. Das 590 decisões, 457 já possuíam patente americana concedida pelo USPTO, sendo que 388 (85\%) acabaram sendo deferidas no INPI. 309 delas haviam obtido patentes européias, das quais 279 (90\%) foram deferidas e apenas $30(10 \%)$ indeferidas. 
Apropriação tecnológica na economia do conhecimento: inovação e propriedade intelectual de software...

Tabela 3

Pedidos de patentes relativas a programas de computador. INPI Brasil

\begin{tabular}{l|c|c|c}
\hline Origem & Pedidos totais & Patente concedida & Não concedida \\
\hline \multirow{2}{*}{ Residentes } & 78 & 14 & 64 \\
& $(13 \%)$ & $(18 \%)$ & $(82 \%)$ \\
\multirow{2}{*}{ Não residentes } & 512 & 425 & 87 \\
& $(87 \%)$ & $(83 \%)$ & $(17 \%)$ \\
\hline \multirow{2}{*}{ Total } & 590 & 439 & 151 \\
& $100 \%$ & $(74 \%)$ & $(26 \%)$ \\
\hline
\end{tabular}

Fonte: SINPI.

Podemos observar que apenas 14 patentes de software (3\% do total) foram concedidas a residentes no país. Nenhuma empresa ou instituição brasileira detém mais de duas patentes de software, o que revela a pouca importância atribuída a esse mecanismo de apropriação no âmbito local. Questionada sobre esse fato, uma empresa nacional entrevistada revelou que, embora nunca tenha solicitado patente no país, já possui um título nos Estados Unidos. A patente foi obtida apenas para evitar conflitos com eventuais detentores de direitos de propriedade intelectual nas exportações de software.

Podemos concluir que as patentes de software no Brasil representam uma simples extensão de direitos de propriedade já obtidos em outros países. O sistema local acaba por dar vigência e eficácia às patentes concedidas no exterior, sem representar um efetivo estímulo à atividade inventiva local.

\section{A questão da pirataria}

Em uma economia crescentemente baseada na informação e no conhecimento, a apropriação de ativos intangíveis por meio de direitos de propriedade é um tema de crescente importância nas relações internacionais. Visando monitorar o movimento de cópias não autorizadas, conscientizar a opinião pública sobre ilegalidade e pressionar governos nacionais a combater a pirataria por meio de ações penais, empresas de software criaram associações em toda a América Latina. No plano político, além de angariar apoio local, tais associações contam com apoio tácito dos governos de seus países de origem. $\mathrm{O}$ governo norte-americano, em particular, criou a US Special 301 Priority Watch List com o objetivo de dar consistência legal a ações de retaliação comercial a países suspeitos de praticarem pirataria de software. Atualmente, o México é um dos países latino-americanos incluídos na lista.

Um estudo da Business Software Association (IDC \& BSA, 2005, p. 14) estima que a perda das empresas de software com as cópias não autorizadas na América Latina atingiu US\$ 2 bilhões em 2005. Tal estimativa é feita com base na avaliação do número de cópias piratas em circulação multiplicadas pelo preço da 
Paulo Bastos Tigre / Felipe Silveira Marques

licença original. Comparativamente, as perdas com a pirataria de software na América Latina seriam, em linhas gerais, equivalentes ao estimado para o Oriente Médio e África (US\$ 1,6 bilhão) e para o Leste Europeu (US\$ 3 bilhões). As perdas em países desenvolvidos seriam de US\$ 6,9 bilhões nos Estados Unidos, US\$ 3,2 bilhões na França, US\$ 1,9 bilhão na Alemanha e US\$ 1,8 bilhão no Reino Unido. Porém, como o mercado desses países é maior, as perdas estimadas nos países em desenvolvimento são mais significativas em termos relativos. $\mathrm{O}$ estudo avalia que a taxa de pirataria chega a $68 \%$ na América Latina contra $36 \%$ na União Européia.

Entretanto, tais estimativas de pirataria estão provavelmente superestimadas. López e Ramos (2007, p. 84-88) criticam os cálculos da BSA por partirem da hipótese de que as cópias piratas existentes em circulação seriam alternativamente compradas a preços de mercado. Para esses autores, uma estimativa mais realista deveria levar em conta as vendas que as empresas efetivamente deixaram de realizar em consequência da pirataria. Nesse sentido, é razoável supor que muitos consumidores que copiaram ou compraram softwares piratas a um preço inferior ao original não estariam dispostos a pagar o preço cheio das licenças oficiais. Caso a pirataria fosse efetivamente controlada, muitos usuários simplesmente deixariam de usar programas proprietários. Este argumento, já levantado na literatura, sugere que as cópias não autorizadas ajudam a difundir padrões tecnológicos proprietários em países emergentes. Apesar de não gerarem receitas imediatas, o uso não autorizado dos programas contribui para o feedback positivo, gerando efeitos de rede essenciais para a consolidação de padrões no mercado.

A pirataria afeta principalmente as empresas que vendem pacotes genéricos. Já as empresas que prestam serviços ou que customizam produtos para seus clientes, estão menos preocupadas com cópias ilegais. Uma pesquisa conduzida por Chudnovsky et. al. (2001) na Argentina revelou que 60\% das 39 empresas locais desenvolvedoras de software entrevistadas alegaram não serem afetadas por pirataria por parte dos usuários, enquanto metade delas não temia a pirataria de competidores. Na medida em que seus programas precisam ser adaptados às necessidades dos clientes, o produto em si não tem valor de revenda para imitadores pouco qualificados tecnicamente.

A principal alternativa para os usuários de software que não querem se submeter às condições de licenciamento e às restrições técnicas impostas pelos fornecedores de software proprietário é o software livre ou aberto. Os modelos de negócios baseados nesse tipo de licença partem do princípio de que o valor está no serviço e não no produto. Adotado inicialmente por pequenas empresas, vem ganhando adeptos entre âncoras da indústria, como a IBM e a Sun. Os programas são doados ou licenciados a preços simbólicos aos clientes em troca de contratos 
de prestação de serviços. Empresas usuárias não necessitam apenas do programa, mas principalmente de serviços técnicos e tecnológicos como o desenvolvimento e implementação de interfaces com sistemas legados, adaptação dos programas às características das empresas, serviços de manutenção, treinamento e consultoria. Assim, as receitas de royalties são substituídas por serviços ao cliente.

\section{Conclusões}

A América Latina vem aumentando gradativamente sua participação na indústria global de software e serviços graças à disponibilidade de recursos humanos qualificados a custos relativamente baixos e a um mercado interno em franco crescimento. A principal área de oportunidade para os países da região reside na prestação de serviços, já que os pacotes de software são monopolizados por poucas empresas globais. Pelo fato de ser caro de produzir e barato de reproduzir, o software produto usufrui grandes economias de escala e escopo. Além disso, o feedback positivo e os efeitos de rede conduzem à lógica do "vencedor leva tudo".

O fortalecimento dos mecanismos de apropriação interessa essencialmente a empresas de pacotes que praticamente não produzem na América Latina. As grandes empresas multinacionais que efetivamente produzem e geram divisas na região são predominantemente voltadas à prestação de serviços de outsourcing, um ramo de negócios que tem pouca necessidade de proteção patentária. As empresas nacionais de software tampouco consideram as patentes importantes. Elas se utilizam essencialmente de procedimentos técnicos e a proteção por patente só é considerada importante quando exportam para os Estados Unidos.

Assim, levando em conta os interesses regionais, um regime de baixa apropriabilidade tecnológica é mais favorável à inovação, dado o caráter cumulativo e modular das soluções. Como o desenvolvimento de software se baseia no aproveitamento de componentes preexistentes, a patente desses subsistemas inibe a inovação, seja pelo alto custo de licenciamento ou pela proibição de utilização de determinados componentes. As patentes de software concedidas em todo o mundo são geralmente consideradas de má qualidade, pois os bancos de dados utilizados na busca dos Escritórios de Patentes não contemplam grande parte do estado da técnica para software. Assim, o procedimento de exame de patente na aferição de novidade e não obviedade é precário, permitindo que softwares que já fazem parte do estado da técnica sejam apropriados indevidamente.

Esse fato, entretanto, não justifica o desrespeito a leis e acordos internacionais. Nesse aspecto, a maioria dos países latino-americanos se enquadra nas orientações do acordo TRIPS de proteger os produtos contra a pirataria por 
meio de copyrights. Tais países alteraram suas legislações na década de 90 para se adaptar às exigências multilaterais e hoje se observa uma significativa homogeneidade nas legislações. Entretanto, o controle legal de cópias não autorizadas é difícil até mesmo em países desenvolvidos, fato que vem levando muitas empresas a adotarem formas técnicas de proteção como autenticação digital, criptografia, controle de acesso, segregação de funções e auditoria de sistemas para proteger seus ativos. Outra estratégia é adotar modelos de negócios mais apoiados em software livre e na prestação de serviços.

Apesar do enquadramento às normas internacionais, os países membros da Organização Mundial do Comércio (OMC) vêm enfrentando crescentes pressões para aumentar a proteção aos direitos de propriedade de programas de computador (Shadlen; Schrank; Kurtz, 2005). Tais pressões vêm dando frutos, principalmente no Brasil, que responde por mais da metade do mercado latino-americano de software. Outro aspecto importante na agenda comercial dos países latinoamericanos é a questão das perdas na indústria de software motivadas pela pirataria. As estimativas são superestimadas em função da metodologia adotada, mas mesmo assim servem de base para ameaças de retaliação comercial. Isso, entretanto, não quer dizer que a pirataria não deva ser combatida. Assegurar os direitos de propriedade intelectual é uma obrigação do Estado e da Justiça.

Em síntese, a propriedade intelectual é um instrumento legal que busca garantir a apropriação tecnológica diante dos riscos e dificuldades enfrentados pelos inovadores. A dinâmica do mercado de software é permanentemente afetada por inovações em rede que ampliam as interfaces, permitindo o surgimento de novas formas de produzir e compartilhar informação e conhecimento. Em consequência, o mercado se subdivide com a criação de novos segmentos, como o de software aberto, gerando modelos de negócios e padrões de competição significativamente distintos.

Nesse contexto, as instituições responsáveis pela concessão de patentes se defrontam com o desafio de harmonizar interesses conflitantes que transcendem o aspecto técnico. Por um lado, precisam atender à demanda das grandes empresas por maior proteção, segundo as legislações e os acordos internacionais vigentes. Por outro, é necessário levar em conta que as mudanças tecnológicas exigem a abertura de espaço no mercado para novas formas cooperativas de produção internacional de conhecimentos digitalmente codificados. Uma excessiva restrição à circulação de conhecimentos poderá dificultar essa missão.

\section{Bibliografia}

ALVAREZ, V. Oportunidades y desafíos de la industria de software en Chile. Informe para o projeto "Oportunidades e Desafios da Indústria de Software na América Latina". Cepal, 2007. 
ANDRADE, E. et. al. Evolução e perspectivas da propriedade intelectual em software. Revista Brasileira de Inovação, Rio de Janeiro, v. 6, n. 1, jan./jun. 2007.

CAMTIC. Estado Nacional Software 2005: Estadísticas Sectoriales de Costa Rica. CAMTIC, 2006.

CARNEIRO, A. M. Proteção de ativos na indústria de software: estratégias e tendências de propriedade intelectual. Tese (Doutorado)-Instituto de Geociências da Universidade Estadual de Campinas, 2007.

CORREA, C. M. Políticas institucionales en materia de propiedad intelectual y transferencia de tecnología. Reunión Regional Ompi-Cepal de Expertos Sobre el Sistema Nacional de Innovación, Propiedad Intelectual, Universidad Y Empresa. Santiago, Oct. 2003.

CHUDNOVSKY, D.; LÓPEZ, A.; MELITSKO, Y S. El sector de software y servicios informáticos en la Argentina. Situación actual y perspectivas de desarrollo. Buenos Aires: CENIT, 2001. (Documento de Trabajo, n. 27).

DOSI, G.; FAILLO, M; MARENGO, L. Organizational capabilities, patterns of knowledge accumulation and governance structures in business firms. An introduction. Laboratory of Economics and Management (LEM). Pisa: Sant 'Anna School of Advanced Studies, 2003. (LEM Papers Series 2003/11).

GONZÁLEZ, I. Oportunidades y desafíos de la industria de software en Uruguay. Informe para o projeto "Oportunidades e Desafios da Indústria de Software na América Latina". Cepal, 2007.

IDC \& BSA. Expanding the frontiers of our digital future: reducing software piracy to accelerate global IT benefits. 2005.

Third annual BSA and IDC global software piracy study. 2006.

LEMOS, R. Direito, tecnologia e cultura. FGV Editora, 2005.

LÓPEZ, A.; RAMOS, D. Oportunidades y desafíos de la industria de software en Argentina. Informe para o projeto "Oportunidades e Desafios da Indústria de Software na América Latina". Cepal, 2006.

MARQUES, F. Oportunidades e desafios da indústria de software no Brasil. Informe para o projeto "Oportunidades e Desafios da Indústria de Software na América Latina". Cepal, 2007.

MENDES, C. Software livre e inovação tecnológica: uma análise sob a perspectiva da propriedade intelectual. Dissertação (Mestrado)-Instituto de Economia da Universidade Estadual de Campinas, 2006.

MIRELES, M. La industria de software en Ecuador. Informe para o projeto “Oportunidades e Desafios da Indústria de Software na América Latina". Cepal, 2006.

MOWERY, D.; ROSENBERG, N. Trajetórias da inovação: a mudança tecnológica nos Estados Unidos da América no século XX. Campinas: Editora Unicamp, 2005. (Série Clássicos da Inovação). 
Paulo Bastos Tigre / Felipe Silveira Marques

MOCHI, P.; HUALDE, A. Oportunidades y desafíos de la industria de software en México. Informe para o projeto "Oportunidades e Desafios da Indústria de Software na América Latina". Cepal, 2007.

OCDE. Frascati Manual: proposed standard practice for surveys on research and experimental development. 2002.

OECD Information Technology Outlook 2006. 2006.

PEDROSO JÚNIOR, M.; VENDRUSCULO, L.; CAMARGO NETO, J. Propriedade intelectual na era digital: questões e tendências. Cadernos de Ciência \& Tecnologia, Brasília. v. 15. n. especial, p. 117-130, 1998.

RODRÍGUEZ, K. La industria de software en Colombia. Informe para o projeto "Oportunidades e Desafios da Indústria de Software na América Latina". Cepal, 2007.

ROSELINO, J. A indústria de software: o "modelo brasileiro" em perspectiva comparada. Tese (Doutorado)-Instituto de Economia da Universidade Estadual de Campinas, 2006.

SHADLEN, K.; SCHRANK, A.; KURTZ, M. The political economy of intellectual property protection: the case of software. Ohio State University, 2005.

SHAPIRO, C.; VARIAN, E. Economia da informação. Rio de Janeiro: Editora Campus, 1999.

SILVA, D. O conflito de interesses na proteção do software por patentes: o caso da União Européia. Dissertação (MBA em Análise de Políticas Públicas em Inovação e Propriedade Intelectual)-Universidade Federal do Rio de Janeiro/INPI, 2007.

TIGRE, P.; MARQUES, F. A indústria de software e serviços na América Latina: uma visão de conjunto. Informe para o projeto "Oportunidades e Desafios da Indústria de Software na América Latina". Cepal, 2007.

VALIMAKI, M. The rise of open source licensing: a challenge to the use of intellectual property in the software industry. Turre Publishing, 2005.

VEIGA, R. Comentários sobre a nova Lei do software. Sindicato das Empresas de Processamento de Dados do Rio Grande do Sul. Disponível: em: http://www.seprors.com.br/parecer.htm. Acesso em: 1 jul. 1998.

WITSA. Digital Planet 2006: the global information economy. May, 2006.

WIPO. Intellectual property handbook: police, law and use. 2004. 